\title{
Efeitos do Fornecimento de Monensina e Óleo de Soja na Dieta sobre o Desempenho de Vacas Leiteiras na Fase Inicial da Lactação ${ }^{1}$
}

\author{
Eduardo da Costa Eifert ${ }^{2}$, Rogério de Paula Lana ${ }^{3}$, Dante Pazzanese Duarte Lanna 4 , Pedro \\ Braga Arcuri ${ }^{5}$, Maria Ignez Leão ${ }^{3}$, Sebastião de Campos Valadares Filho ${ }^{3}$, Webel Machado \\ Leopoldino $^{6}$, José Henrique Souza da Silva ${ }^{7}$
}

\begin{abstract}
RESUMO - Avaliou-se o efeito do fornecimento de monensina e óleo de soja na dieta sobre o desempenho de vacas leiteiras na fase inicial de lactação. Foram utilizadas 16 vacas multíparas 7/8 Holandês Gir, com 30 dias em lactação, em um delineamento em blocos ao acaso, em esquema fatorial. O período experimental teve duração de 84 dias, divididos em três fases: I - $5^{\mathrm{a}}$ à $8^{\mathrm{a}}$; II - $9^{\mathrm{a}}$ à $12^{\mathrm{a}}$; III - $13^{\mathrm{a}}$ à $16^{\mathrm{a}}$ semana de lactação. Os tratamentos foram denominados: CT: dieta controle - sem óleo e sem monensina; MN: dieta sem óleo, com monensina a 33 ppm; OL - dieta com óleo de soja (3,9\%), sem monensina; OM - dieta com a combinação de óleo de soja e monensina. Os animais foram alimentados duas vezes ao dia, com dieta composta por $52 \%$ de silagem de milho e $48 \%$ de concentrado. O consumo foi reduzido nas vacas alimentadas com as dietas com óleo de soja, mas o consumo de energia não foi alterado pelos tratamentos. A produção de leite foi similar entre os animais, mas, enquanto as dietas sem óleo proporcionaram aumento no consumo e na produção com o avanço da lactação, nas dietas com óleo o consumo e produção de leite foram constantes. O óleo de soja reduziu a produção de leite corrigida e tanto monensina como óleo reduziram o teor de gordura, que diminuiu nas fases II e III nas vacas que receberam as dietas com óleo e aumentou naquelas alimentadas com as dietas sem óleo. A monensina elevou o teor de proteína, enquanto o óleo de soja reduziu a concentração e produção de proteína. As dietas com óleo de soja mostraram maior eficiência bruta e menor eficiência energética, indicando que a energia da produção de leite foi direcionada ao ganho de peso.
\end{abstract}

Palavras-chave: composição do leite, ionóforos, lipídios, produção de leite

\section{Effects of Dietary Supplementation of Monensin and Soybean Oil on Production of Early Lactating Dairy Cows}

\begin{abstract}
Sixteen 7/8 Holstein-Zebu multiparous cows averaging 30 DIM were used in a complete randomized block design with a 2 x 2 factorial arrangement to study the effects of supplementing monensin and/or soybean oil on production of early lactating dairy cows. The experimental period lasted 84 days and was divided in three phases as follows: I - $5^{\text {th }}$ to $8^{\text {th }}$, II $-9^{\text {th }}$ to $12^{\text {th }}$, and III $-13^{\text {th }}$ to $16^{\text {th }}$ week of lactation. The following treatments were used: control diet without monensin and soybean oil (CT); diet with 33 ppm of monensin with no soybean oil (MN); diet with 3.9\% of the dry matter (DM) as soybean oil with no monensin (OL); or diet with a combination of soybean oil and monensin (OM). Cows were fed twice a day a diet containing 52\% of corn silage and 48\% of concentrate on DM basis. Although energy intake did not differ across treatments, DMI was reduced on cows fed diets supplemented with soybean oil. Despite similar milk yield among treatments, cows fed diets not supplemented with soybean oil increased both DMI and milk production as lactation advanced while no changes were observed for those fed diets containing soybean oil. Feeding soybean oil to early lactating dairy cows reduced corrected milk yield whereas content of milk fat decreased when either monensin or soybean oil was added to the diet; milk fat content was reduced in phases II and III of lactation on diets with supplemental fat while the opposite was observed on diets with no fat inclusion. Feeding monensin increased milk protein content but milk protein content and yield were both reduced by feeding soybean oil to dairy cows. Diets supplemented with soybean oil had greater feed efficiency but their lower energetic efficiency suggested that energy was switched from milk yield to weight gain in the current trial.
\end{abstract}

Key Words: ionophores, lipids, milk composition, milk yield

\section{Introdução}

Maximizar o consumo de energia na fase inicial da lactação é importante para o animal minimizar a mobilização de gordura corpórea e alcançar o pico de lactação, sem prejuízos na saúde e na persistência da lactação (Knowlton et al., 1996).

Elevar o nível de concentrado é a prática mais recomendada. Entretanto, altas quantidades de carboidratos não-estruturais podem acarretar desor-

\footnotetext{
${ }^{1}$ Financiado pelo CNPq, processo $477530-01 / 0$ (NV).

2 Post-Doc ESALQ-USP, bolsista FAPESP (eifert@esalq.usp.br).

3 Professor DZO-UFV, CEP: 36571.000 - Viçosa - MG (rlana@ufv.br).

${ }^{4}$ Professor ESALQ-USP (dpdlanna@esalq.usp.br).

5 Pesquisador EMBRAPA Gado de Leite, Juiz de Fora - MG.

${ }^{6}$ Professor DZ-UFSM

7 Professor UNIP-SP.
} 
dens metabólicas e ruminais, influenciando negativamente o consumo e a produção leiteira (NRC, 2001). Como alternativa, o aumento na concentração energética das dietas pelo uso de gordura (Drackley, 1999) e a adição de ionóforos (McGuffey et al., 2001) têm apresentado perspectivas interessantes para melhorar o status energético de vacas em início de lactação.

Os ionóforos elevam a participação de bactérias Gram-negativas no rúmen, alterando os produtos finais da fermentação, pelo aumento da proporção de propionato e pela redução das proporções de acetato e butirato e da produção de metano em até 30\%. Como conseqüência, ocorre aumento da energia líquida das dietas (McGuffey et al., 2001). Os estudos de Ipharraguerre \& Clark (2003) indicam que a monensina aumenta as concentrações plasmáticas de glicose e reduz a quantidade no plasma de ácidos graxos não-esterificados e de corpos cetônicos, que estão associados à redução no consumo no início da lactação (Drackley, 1999).

As pesquisas que envolvem ionóforos para vacas em lactação têm produzido resultados divergentes, indicando haver interações entre os fatores dietéticos e fisiológicos envolvidos (Ipharraguerre \& Clark, 2003). As revisões de Ipharraguerre \& Clark (2003) e McGuffey et al. (2001) sugerem que a redução no consumo, característica verificada em bovinos de corte, parece ser mais freqüente quando as vacas estão no terço médio ao final da lactação. No início da lactação, a utilização de monensina reduziu em $2 \%$ o consumo e aumentou a produção de leite em 9,2\% (Phipps et al., 2000). Também no início da lactação, Duffield et al. (1999) verificaram que a resposta à monensina foi dependente do escore corporal: enquanto não observaram resposta em vacas com escore corporal $\leq 3,25$, verificaram aumentos de $1,5 \%$ na produção de leite em vacas com escores entre 3,25 e 3,75 e de 7,4\% naquelas com escores de 3,75.

Por sua densidade energética, gorduras são fornecidas a vacas lactantes e as respostas esperadas na produção de leite são influenciadas por vários fatores, incluindo a dieta basal, a fase da lactação, o balanço energético, a composição e a quantidade de gordura suplementar (NRC, 2001). No início da lactação, a gordura é fornecida para elevar o consumo de energia metabolizável e reduzir a mobilização corpórea, sendo utilizada preferencialmente para síntese de leite adicional (Benson et al., 2001).

As respostas positivas na produção de leite são obtidas geralmente com a utilização de gorduras iner- tes à função ruminal, sobretudo as saturadas, que também apresentam pouca influência sobre o consumo. Quando óleos vegetais são fornecidos, há freqüente redução no consumo (Allen, 2000), mesmo quando na forma de sais de cálcio (Benson et al., 2001), o que pode reduzir a ingestão total de energia, refletindo em menor produção (Allen, 2000). Por outro lado, muitos pesquisadores têm direcionado sua atenção aos efeitos dietéticos de gorduras insaturadas, visando alterar o perfil dos lipídios do leite, procurando atender à demanda por leite com menor quantidade de ácidos graxos saturados e elevadas concentrações de ácidos graxos insaturados e ricos em CLA cis-9 trans-11 $\mathrm{C}_{18: 2}$, refletindo a tendência mundial de consumo de produtos lácteos com propriedades nutracêuticas, com benefícios potenciais à saúde humana.

Estudos envolvendo a interação entre gordura e ionóforos em gado de leite são escassos e aqueles disponíveis foram realizados com animais com produção média diária de 25 kg. Johnson et al. (1988) observaram que a inclusão simultânea na dieta de lasalocida e amendoim em grão, como fonte de lipídios, reduziu o consumo em 21\%. Cant et al. (1997) notaram efeito sinérgico negativo da monensina e do óleo de peixe sobre o consumo. Entretanto, não observaram diferenças significativas na produção de leite, o que resultou em melhor eficiência de produção. Em vacas no terço médio da lactação, Eifert et al. (2005) observaram que o consumo foi reduzido em $16 \%$ e a produção em $21 \%$, o que indica também efeitos sinérgicos negativos da combinação de óleo de soja e monensina.

Segundo Knolton et al. (1996), a produção e o consumo na fase inicial da lactação podem não refletir aqueles resultados observados em pesquisas realizadas no terço médio da lactação, pois o volume ruminal, a taxa de passagem do alimento pelo rúmen, a exigência de nutrientes e o status energético são diferentes. O objetivo neste trabalho foi estudar o efeito da combinação de óleo de soja e monensina nas dietas sobre a produção, o consumo e a composição do leite de vacas na fase inicial da lactação e avaliar se estas variáveis se modificam com o avançar da lactação.

\section{Material e Métodos}

O experimento foi conduzido no Campo Experimental de Coronel Pacheco - EMBRAPA Gado de Leite, no período de maio a agosto de 2002, e as 
análises laboratoriais foram realizadas no Laboratório de Nutrição Animal do Departamento de Zootecnia da Universidade Federal de Viçosa.

Foram utilizadas 16 vacas multíparas 7/8 HolandêsGir, com peso inicial de $472 \pm 41 \mathrm{~kg}$ e $29,9 \pm 9$ dias em lactação. O delineamento experimental foi em blocos ao acaso, em um arranjo fatorial $2 \times 2$, que consistiu no fornecimento ou não de monensina sódica, (33 ppm) e/ ou de óleo de soja (4,0\%). Os tratamentos foram denominados: CT: dieta controle, sem óleo e sem monensina; MN: dieta sem óleo, com monensina; OL: dieta com óleo, sem monensina; OM: dieta com óleo e monensina.

A proporção dos ingredientes e a composição químico-bromatológica das dietas encontram-se na Tabela 1. A alimentação consistiu de silagem de milho (52\%) e concentrado (48\%) e foi formulada para atender ou exceder as recomendações do NRC (2001) para vacas com produção de $25 \mathrm{~kg} /$ dia e 3,5\% de gordura. Semanalmente, o óleo de soja foi misturado ao concentrado, enquanto a monensina foi adicionada ao concentrado no momento da alimentação.

Os animais foram mantidos em confinamento e alimentados duas vezes ao dia (8 h e 15h30) em igual proporção, sendoa alimentação fornecida individualmente em cochos com controle eletrônico individual, tipo “Calan Gate” (Calan Data Ranger $\left.{ }^{\circledR}\right)$. O nível de oferta foi ajustado para se manter $10 \%$ de sobras, que, diariamente, foram retiradas, pesadas e amostradas, elaborando-se uma amostra composta, que foi imediatamente congelada para posterior análise. Os animais foram ordenhados diariamente às 5 e $15 \mathrm{~h}$.

A produção leiteira foi medida diariamente. Amostras do leite de dois dias de ordenha consecutivos em cada semana foram retiradas, para a avaliação da composição do leite. A composição do leite foi obtida no Laboratório de Qualidade do Leite da EMBRAPA Gado de Leite por meio da análise por espectrometria na faixa do infravermelho em um aparelho Bentley 2000. Para o cálculo da produção de leite corrigida para 3,5\% de gordura, utilizou-se a fórmula citada por Leiva et al. (2000), PLcorr $=(12,82 *$ Pgord $)+$ $(7,13 *$ Pptn $)+\left(0,323^{*} \mathrm{PL}\right)$, em que: $\mathrm{PL}=$ produção de leite, $\mathrm{kg} / \mathrm{dia}$; Pgord = produção de gordura, kg/dia; e Pptn = produção de proteína, $\mathrm{kg} /$ dia .

Os animais foram pesados em intervalos de duas semanas, imediatamente após a ordenha matinal, quando também foram classificados quanto ao escore corporal, de acordo com o NRC (2001). O balanço energético (Mcal/dia) foi calculado como a seguir:
Tabela 1 - Ingredientes e composição química das dietas experimentais

Table 1 - Ingredient and chemical composition of experimental diets

\begin{tabular}{|c|c|c|}
\hline \multirow[t]{2}{*}{ Item } & \multicolumn{2}{|c|}{$\begin{array}{l}\text { Dieta } \\
\text { Diet }\end{array}$} \\
\hline & $\begin{array}{c}\text { Sem óleo } \\
\text { Without oil }\end{array}$ & $\begin{array}{c}\text { Com óleo } \\
\text { With oil }\end{array}$ \\
\hline \multicolumn{3}{|l|}{ Ingrediente, \% } \\
\hline $\begin{array}{l}\text { Ingredient, \% } \\
\text { Silagem de milho } \\
\text { Corn silage }\end{array}$ & 52,1 & 51,7 \\
\hline $\begin{array}{l}\text { Milho triturado } \\
\text { Cracked corn }\end{array}$ & 19,2 & 17,7 \\
\hline $\begin{array}{l}\text { Farelo de soja } \\
\text { Soybean meal }\end{array}$ & 17,4 & 16,0 \\
\hline $\begin{array}{l}\text { Farelo de trigo } \\
\text { Wheat bran }\end{array}$ & 4,0 & 3,7 \\
\hline $\begin{array}{l}\text { Sorgo } \\
\text { Sorghum }\end{array}$ & 3,0 & 2,8 \\
\hline $\begin{array}{l}\text { Farelo de algodão } \\
\text { Cottonseed meal }\end{array}$ & 2,2 & 2,0 \\
\hline $\begin{array}{l}\text { Óleo de soja } \\
\text { Soybean oil }\end{array}$ & 0,0 & 3,9 \\
\hline $\begin{array}{l}\text { Uréia } \\
\text { Urea }\end{array}$ & 0,7 & 1,0 \\
\hline $\begin{array}{l}\text { Sulfato de amônia } \\
\text { Ammonium sulfate }\end{array}$ & 0,1 & 0,1 \\
\hline $\begin{array}{l}\text { Minerais }{ }^{1} \\
\text { Minerals }\end{array}$ & 1,3 & 1,1 \\
\hline
\end{tabular}

Composição química, \%

Chemical composition, \%

\begin{tabular}{lcc}
\hline FDN (NDF) & 35,9 & 35,2 \\
FDA (ADF) & 21,7 & 21,2 \\
Proteína bruta & 18,2 & 18,0 \\
$\begin{array}{l}\text { Crude protein } \\
\text { Extrato etéreo }\end{array}$ & \\
Ether extract & 2,8 & 6,4 \\
NDT $(T N D)$ & & \\
ELL $(N E L)^{2}$ & 69,7 & 74,1 \\
\hline
\end{tabular}

1 Sal branco 40\%; calcário 36\%; fosfato bicálcico 16\%; por kg: $80 \mathrm{mg}$ de Co; 400 mg de Cu; 200 mg de I, 6000 mg de Mn; 400 mg de Se; 800 mg de Zn; 3,85 UI de vitamina A; 2,29 UI de vitamina D; 6,54 UI de vitamina $\mathrm{E}$

${ }^{1}$ White salt 40\%; limestone $36 \%$; dicalcium phosphate $16 \%$; per $\mathrm{kg}$ : $80 \mathrm{mg}$ of $\mathrm{Co} ; 400 \mathrm{mg}$ of $\mathrm{Cu} ; 200 \mathrm{mg}$ of I, $6000 \mathrm{mg}$ of $\mathrm{Mn} ; 400 \mathrm{mg}$ of Se; $800 \mathrm{mg}$ of $Z n ; 3,85$ IU of vitamin $A ; 2,29$ IU of vitamin D; 6,54 IU of vitamin $E$.

${ }^{2}$ ELL - Energia líquida de lactação, em Mcal/kg.

${ }^{2} \mathrm{NEL}-$ Net energy for lactation in Mcal/ $\mathrm{kg}$.

consumo de energia líquida de lactação (CEL) energia líquida para mantença - energia secretada no leite. O CEL foi calculado como o consumo diário de matéria seca multiplicado pela concentração de energia líquida de lactação (ELL) das dietas. A ELL foi obtida nas tabelas do NRC (2001). A energia líquida de mantença foi calculada como $0,080 * \mathrm{PV}^{0,75}$ (NRC, 1989). Estimou-se a secreção de energia no leite a 
partir da equação sugerida pelo AFRC (1993): EL $(\mathrm{Mcal} / \mathrm{kg})=(0,0929 * \mathrm{G})+(0,0547 * \mathrm{P})+(0,0395 * \mathrm{~L})$, em que $\mathrm{G}, \mathrm{P}$ e $\mathrm{L}$ são as porcentagens de gordura, proteína e lactose do leite. Os valores encontrados foram multiplicados pela produção de leite, obtendose a secreção diária de energia.

O delineamento experimental foi em blocos ao acaso, com um período de avaliação de 12 semanas. Para a formação dos blocos, foi utilizado como critério o número de gestações, dias em lactação e grupo genético, além da produção e composição do leite obtido na semana anterior ao início do experimento, quando todos os animais receberam a dieta CT por 10 dias. Para a análise dos resultados, dividiu-se o período experimental em três fases da lactação: I - $5^{\text {a }}$ à $8^{\mathrm{a}}$; II - $9^{\mathrm{a}}$ à $12^{\mathrm{a}}$; III $-13^{\mathrm{a}}$ à $16^{\mathrm{a}}$ semana de lactação.

Para a análise dos dados, foram incluídos no modelo os efeitos das dietas, dos blocos e da fase, por meio do comando Proc GLM do SAS (1999). Para a avaliação dos efeitos das dietas em relação às fases estipuladas, utilizou-se a interação oleo*mon*bloco como erro 'B'. Nas tabelas, os efeitos principais estão reportados com os níveis de significância menores que 5\%, exceto quando reportados por algum interesse na discussão.

\section{Resultados e Discussão}

Para todas as variáveis testadas, não foram verificados efeitos significativos $(\mathrm{P}>0,20)$ para interações óleo*monensina e monensina*fase e para a interação tripla óleo*monensina*fase.
Constam na Tabela 2 as médias dos consumos de matéria seca e de energia para as diferentes dietas experimentais. Não foi verificado efeito de monensina $(\mathrm{P}>0,20)$ sobre estas variáveis. No entanto, o consumo de matéria seca (17,6 vs 15,4 kg/dia) e o consumo percentual (3,56 vs 3,14 kg/100 kg PV) foram menores nas dietas com óleo de soja $(\mathrm{P}<0,05)$.

A diminuição no consumo de matéria seca em vacas lactantes ocasionada pela inclusão de óleos vegetais tem sido observada, mas sua causa ainda não está bem estabelecida. Freqüentemente, a explicação é relacionada à interferência dos lipídios insaturados sobre a atividade das bactérias Gram-positivas, principais envolvidas na fermentação da fibra (Cant et al., 1997). Assim, há aumento do efeito de enchimento ruminal e redução do consumo (Jenkins, 1993). Entretanto, ainda que tenham sido verificadas reduções na síntese microbiana e na digestão ruminal da FDN nas dietas com óleo e monensina, Eifert et al. (2005) afirmaram que, com a redução do consumo, efeitos metabólicos podem ter interagido nestas dietas.

Neste sentido, Bateman \& Jenkins (1998) comprovaram que se há adequado nível de FDN, o uso de dietas com até $8 \%$ de óleo de soja tem pouco efeito sobre a fermentação ruminal. Benson et al. (2001) reportaram vários experimentos com infusões pósruminais de ácidos graxos, mostrando a influência do perfil de ácidos graxos sobre o consumo. Segundo esses autores, os ácidos graxos poliinsaturados $\left(\mathrm{C}_{18: 2} \mathrm{e}\right.$ $\mathrm{C}_{18: 3}$ ) apresentam maior efeito supressor no consumo queos ácidos graxos saturados ou monoinsaturados $\left(\mathrm{C}_{18: 1}\right)$.

Tabela 2 - Médias observadas, desvio-padrão e efeitos principais da combinação de óleo de soja e monensina na dieta sobre o consumo de matéria seca e de energia

Table 2 - Observed means, standard error and main effects of the dietary supplementation of soybean oil and monensin on intakes of dry matter and energy

\begin{tabular}{|c|c|c|c|c|c|c|c|c|}
\hline \multirow[t]{2}{*}{ Item } & \multicolumn{4}{|c|}{$\begin{array}{l}\text { Média dos tratamentos }{ }^{1} \\
\quad \text { Mean of treatments }{ }^{1}\end{array}$} & \multirow[t]{2}{*}{$\begin{array}{l}\text { DPM } \\
\text { SEM }\end{array}$} & \multicolumn{3}{|c|}{$\begin{array}{c}\text { Efeito }(\mathrm{P})^{2} \\
\text { Effect }(P)\end{array}$} \\
\hline & CT & MN & OL & $\mathrm{OM}$ & & $\mathrm{M}$ & $\mathrm{O}$ & $\mathrm{MxO}$ \\
\hline $\begin{array}{l}\text { Consumo diário } \\
\text { Daily intake }\end{array}$ & & & & & & & & \\
\hline $\begin{array}{l}\text { Matéria seca, kg } \\
\text { Dry matter, } \mathrm{kg}\end{array}$ & 17,3 & 17,8 & 15,4 & 15,4 & 0,81 & NS & $*$ & NS \\
\hline $\begin{array}{l}\text { Consumo percentual, \%PV } \\
\text { Intake, \% of BW }\end{array}$ & 3,58 & 3,53 & 3,20 & 3,07 & 0,19 & NS & $*$ & NS \\
\hline $\begin{array}{l}\text { NDT, } \mathrm{kg} \\
T D N, \mathrm{~kg}\end{array}$ & 12,0 & 12,3 & 11,4 & 11,4 & 0,57 & NS & NS & NS \\
\hline $\begin{array}{l}\text { Energia líquida, Mcal } \\
\text { Net energy, Mcal }\end{array}$ & 26,7 & 27,4 & 26,4 & 26,4 & 1,29 & NS & NS & NS \\
\hline
\end{tabular}

DPM = desvio-padrão da média (SEM = standard error of mean).

${ }^{1} \mathrm{CT}=$ sem óleo ou monensina; MN = monensina a 33 ppm; OL = óleo de soja a 4\% MS; OM = óleo de soja + monensina.

${ }^{1} \mathrm{CT}=$ without oil or monensin; $M N=33 \mathrm{ppm}$ of monensin; $\mathrm{OL}=4 \%$ of DM as soybean oil; OM = with soybean oil and monensin.

${ }^{2} \mathrm{M}=$ monensina; $\mathrm{O}=$ óleo; $\mathrm{M} \times \mathrm{O}=$ interação; $\mathrm{NS}=$ não-significativo $(\mathrm{P}>0,20) ;{ }^{*} \mathrm{P}<0,05$.

${ }^{2} M=$ monensin; $O=$ oil; $M \times O=$ interaction; $N S=$ not significant $(P>0.20) ; * P<0.05$. 
Trabalhos envolvendo monensina e óleo de soja (Eifert et al., 2005) ou óleo de peixe (Cant et al., 1997) mostraram efeitos aditivos do ionóforo e da gordura ao reduzirem o consumo, sem afetar o consumo de energia. Esse mesmo comportamento parece ter ocorrido neste trabalho e a observação de que o consumo de energia líquida ou NDT foi similar entre os tratamentos indica que o consumo foi regulado por algum mecanismo de homeostase energética.

Drackley (1999) sugeriu que a maior mobilização de ácidos graxos não-esterificados no início da lactação interage com a suplementação de lipídios, promovendo maior feedback negativo à oxidação de ácidos graxos no fígado, e que pode causar maior redução no consumo que a suplementação de lipídios no terço médio da lactação, quando as vacas estão com balanço energético positivo.

Não foi verificada interação significativa entre óleo e fase da lactação em relação ao consumo de energia. O consumo de matéria seca e o consumo percentual (Figuras 1A e 1B) nas diferentes fases da lactação comprovam que as dietas sem óleo proporcionaram maior consumo que as dietas com óleo, independentemente da fase da lactação. Nas vacas alimentadas com dietas contendo óleo, o consumo foi maior na 5 à $8^{a}$ semana da lactação que nas demais fases, o que contrapõe a afirmação de Drackley (1999) descrita anteriormente. Benson et al. (2001) não verificaram interação significativa entre a fase da lactação e a infusão abomasal de óleo de girassol e colza sobre o consumo. Entretanto, sugeriram que, aos 55 dias de lactação, os ácidos graxos infundidos foram utilizados para oxidação no fígado, enquanto, aos 111 dias, estes ácidos graxos foram incorporados à gordura do leite ou à composição do ganho de peso. Por outro lado, Gagliostro \& Chilliard (1991) observaram que o efeito depressor da infusão duodenal de óleo de colza sobre o consumo foi mais intenso no terço médio da lactação que na terceira semana pós-parto.

Neste trabalho, embora sem interação significativa, as dietas OL e OM reduziram o consumo percentual em 11,8 e 16,6\% em relação à dieta CT, enquanto Eifert et al. (2005), ao trabalharem com vacas aos 155 dias pós-parto, utilizando os mesmos tratamentos, verificaram reduções de 16,3 e 21,1\%, respectivamente, confirmando as conjecturas de Gagliostro \& Chilliard (1991) acerca da maior supressão no consumo no terço médio da lactação. As dietas com $\mathrm{MN}$ reduziram o consumo percentual em apenas 1,4\% em relação à dieta CT (Tabela 2), coincidindo com o valor observado por Phipps et al. (2000). Não há ainda uma definição clara do efeito de ionóforos sobre o consumo em vacas lactantes, mas, conforme Ipharraguerre \& Clark (2003), espera-se que a monensina promova maior redução no consumo em dietas ricas em concentrado (mais de $50 \%$ ) que naquelas ricas em volumoso, como ocorre em bovinos de corte.

Drackley (1999), ao abordar o período de transição e os efeitos da gordura dietética e da mobilizada sobre a função hepática, citou experimentos com
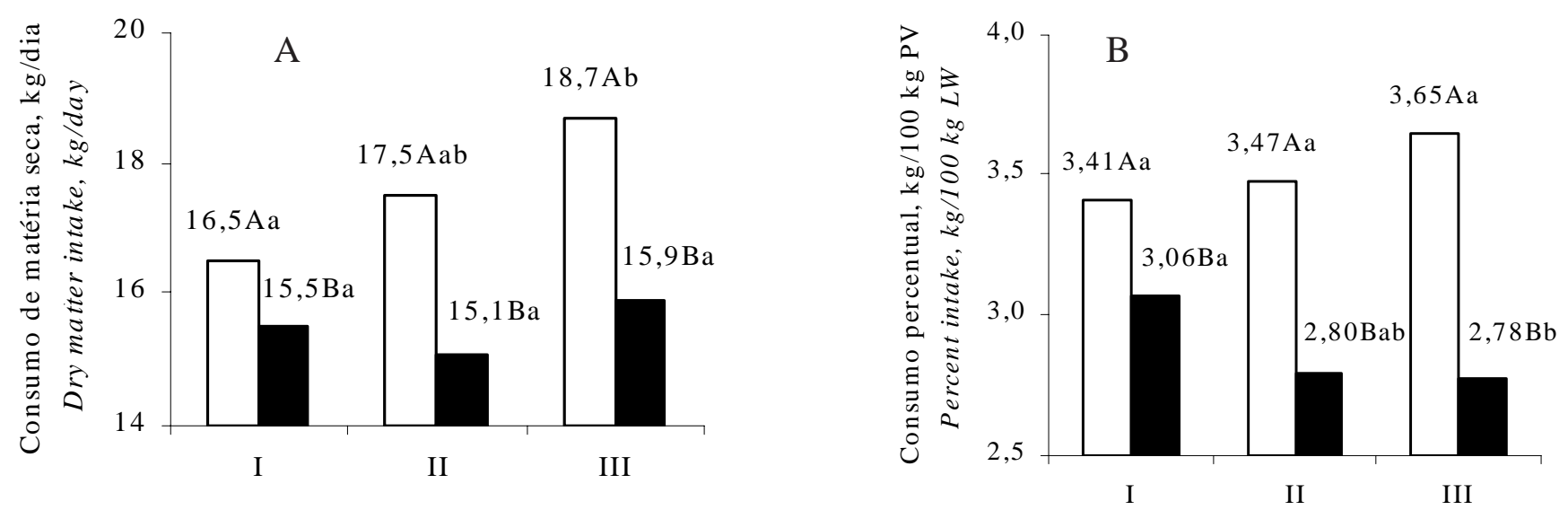

Figura 1 - Representação gráfica da interação óleo x fase da lactação das variáveis: consumo de matéria seca (A) e consumo percentual (B). I, II, III - fase da lactação; $\square$ dietas sem óleo; $\square$ dietas com óleo. A, B - diferença na mesma fase; $a, b$ - diferença dentro do tratamento (Tukey, $\mathrm{P}<0,05$ ).

Figure 1 - Graphic representation of the oil $x$ phase of lactation interaction of dry matter intake (A) and percent intakes (B). I, II, III - phase of lactation; $\square$ diets without oil; $\square$ diets with oil. A, B - difference within phase of lactation; $a, b$ - difference within treatment (Tukey, $P<0.05)$. 
bezerros, em que substitutos do leite suplementados com óleo de soja ocasionaram acúmulo de triglicerídios no fígado, o que não ocorreu com a suplementação com sebo bovino. Segundo esse autor, o perfil de ácidos graxos absorvidos nos intestinos pode influenciar a atividade ou expressão gênica de enzimas e de receptores envolvidos na oxidação de ácidos graxos neste órgão. Neste sentido, é possível que o menor consumo percentual nas fases II e III registrado nas vacas alimentadas com as dietas contendo óleo seja um efeito cumulativo do consumo de óleo de soja com o decorrer do período experimental.

A produção de leite não foi alterada pelas dietas, embora a dieta MN tenha resultado em valor numericamente maior que as demais e $3 \%$ maior que a dieta CT (Tabela 3). No entanto, enquanto a produ- ção de leite das vacas que receberam dietas sem óleo aumentou com o decorrer do período experimental, indicando que os animais passaram pelo seu pico de lactação, a produção daquelas alimentadas com dietas contendo óleo manteve-se constante (Figura 2A). A menor produção de leite nas fases II e III para as vacas que consumiram dietas com óleo, em relação às alimentadas com dietas sem óleo, confirma o relato sobre possíveis efeitos cumulativos dos suplementos lipídicos.

A produção de leite corrigida foi maior nos animais que receberam as dietas sem óleo (25,0 vs $22,0 \mathrm{~kg} /$ dia, Tabela 3), aumentando com o decorrer do período experimental (Figura 2B). As dietas com óleo acarretaram menor produção, que se manteve constante entre as fases avaliadas.

Tabela 3 - Médias observadas, desvio-padrão e efeitos principais da produção, composição e produção de componentes do leite, secreção de energia no leite e eficiência, em função da combinação de óleo de soja e monensina na dieta

Table 3 - Observed means, standard error and principal effects of milk composition and yield, milk component yield, energy secretion and efficiency in function of soybean oil and monensin combination in the diet

\begin{tabular}{|c|c|c|c|c|c|c|c|c|}
\hline \multirow[t]{2}{*}{ Item } & \multicolumn{4}{|c|}{$\begin{array}{l}\text { Média dos tratamentos }{ }^{1} \\
\text { Mean of treatments }\end{array}$} & \multirow[t]{2}{*}{$\begin{array}{l}\text { DPM } \\
\text { SEM }\end{array}$} & \multicolumn{3}{|c|}{$\begin{array}{c}\text { Efeito }(\mathrm{P})^{2} \\
\operatorname{Effect}(P)\end{array}$} \\
\hline & CT & $\mathrm{MN}$ & OL & $\mathrm{OM}$ & & M & $\mathrm{O}$ & $\mathrm{MxO}$ \\
\hline \multicolumn{9}{|l|}{ Leite (Milk) } \\
\hline $\begin{array}{l}\text { Produção, kg/dia } \\
\text { Milk yield, kg/d }\end{array}$ & 25,9 & 26,6 & 24,8 & 25,0 & 1,45 & NS & NS & NS \\
\hline $\begin{array}{l}\text { Produção corrigida, kg } \\
\text { Corrected yield, } k g\end{array}$ & 25,2 & 24,8 & 22,0 & 21,9 & 1,27 & NS & $*$ & NS \\
\hline \multicolumn{9}{|l|}{ Composição do leite, \% } \\
\hline Gordura (Fat) & 3,57 & 3,13 & 2,89 & 2,74 & 0,17 & 0,11 & $* * *$ & NS \\
\hline Proteína (Protein) & 2,79 & 2,94 & 2,74 & 2,80 & 0,03 & $* * *$ & * & NS \\
\hline Lactose (Lactose) & 4,91 & 5,00 & 4,90 & 4,96 & 0,09 & NS & NS & NS \\
\hline $\mathrm{RPG}(P F R)$ & 0,79 & 0,95 & 0,96 & 1,03 & 0,06 & $*$ & $*$ & NS \\
\hline \multicolumn{9}{|c|}{ Produção de componentes, kg/dia } \\
\hline \multicolumn{9}{|l|}{ Milk component yield, $\mathrm{kg} /$ day } \\
\hline Gordura (Fat) & 0,914 & 0,835 & 0,713 & 0,687 & 0,05 & NS & $* * *$ & NS \\
\hline Proteína (Protein) & 0,719 & 0,748 & 0,678 & 0,730 & 0,04 & NS & NS & NS \\
\hline \multicolumn{9}{|l|}{ Eficiência (Efficiency) } \\
\hline $\begin{array}{l}\text { Eficiência bruta } \\
\text { Crude efficiency }\end{array}$ & 1,50 & 1,50 & 1,64 & 1,63 & 0,08 & NS & 0,12 & NS \\
\hline $\begin{array}{l}\text { Eficiência corrigida }{ }^{4} \\
\text { Corrected efficiency }\end{array}$ & 1,47 & 1,39 & 1,45 & 1,45 & 0,08 & NS & NS & NS \\
\hline $\begin{array}{l}\text { Eficiência energética } \\
\text { Energetic efficiency }\end{array}$ & 0,66 & 0,63 & 0,58 & 0,58 & 0,04 & NS & 0,12 & NS \\
\hline $\begin{array}{l}\text { Secreção de energia (Mcal/dia) } \\
\text { Energy secretion (Mcal/day) }\end{array}$ & 17,4 & 17,1 & 15,1 & 15,3 & 0,82 & NS & * & NS \\
\hline
\end{tabular}

DPM = desvio-padrão da média (SEM = standard error of mean).

${ }^{1} \mathrm{CT}=$ sem óleo ou monensina; $\mathrm{MN}=$ monensina a $33 \mathrm{ppm} ; \mathrm{OL}$ = óleo de soja a 4\% MS; OM = óleo de soja + monensina.

${ }^{1} \mathrm{CT}=$ without oil or monensin; $M N=$ monensin at $33 \mathrm{ppm} ; \mathrm{OL}=$ soybean oil at $4 \% \mathrm{DM} ; \mathrm{OM}=$ with soybean oil and monensin.

${ }^{2} \mathrm{M}=$ monensina; $\mathrm{O}=$ óleo; $\mathrm{M} \times \mathrm{O}=$ interação; $\mathrm{NS}=$ não-significativo $(\mathrm{P}>0,20) ;{ }^{*} \mathrm{P}<0,05$.

${ }^{2} M=$ monensin; $O=$ oil; $M \times O=$ interaction; $N S=$ not significant $(P>0.20) ; * P<0.05$.

3 Produção/consumo (yield/intake).

4 Produção corrigida/consumo (corrected yield/intake).

${ }^{5}$ Energia secretada/consumo de energia (secreted energy/ energy intake). 

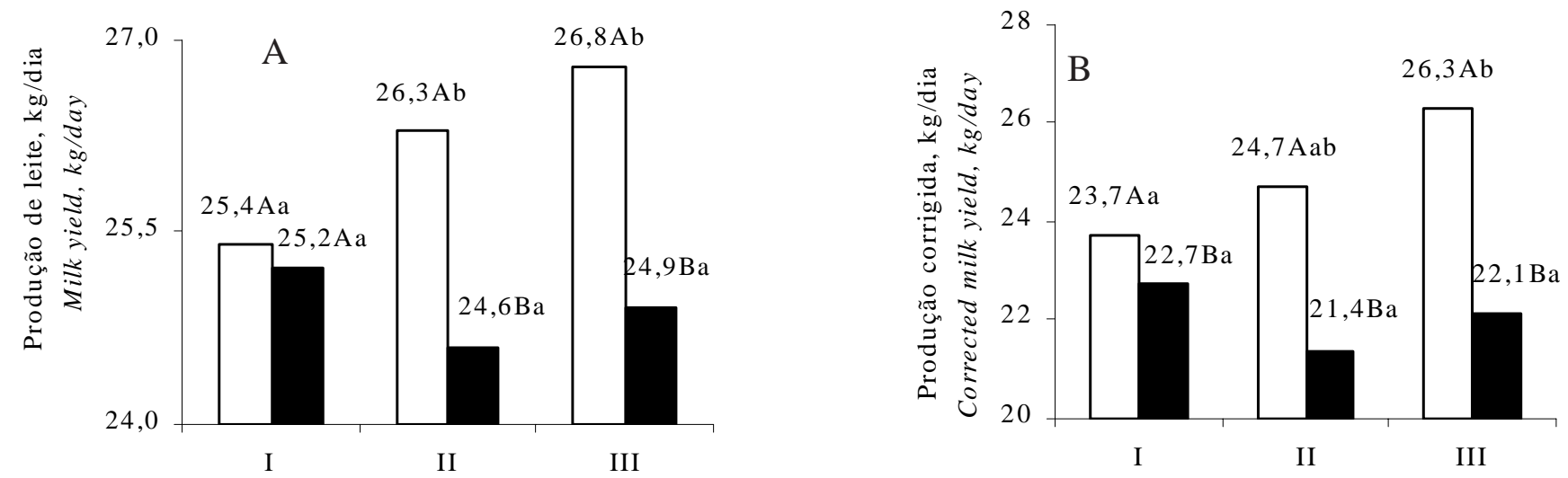

Figura 2 - Representação gráfica da interação óleo x fase da lactação das variáveis: produção de leite (A) e produção corrigida (B). I, II, III - fase da lactação; $\square$ dietas sem óleo; $\square$ dietas com óleo. A, B - diferença na mesma fase; $\mathrm{a}, \mathrm{b}$ - diferença dentro do tratamento (Tukey, $\mathrm{P}<0,05$ ).

Figure 2 - Graphic representation of the oil x phase of lactation interaction of milk yield (A) and corrected milk yield (B). I, II, III phase of lactation; $\square$ diets without oil; $\square$ diets with oil. A, B - difference within phase of lactation; $a, b$ - difference within treatment (Tukey, $P<0.05$ ).

As diferenças observadas para a produção corrigida são reflexos da secreção de componentes do leite (Tabela 3) e os valores similares entre as dietas MN e CT para a produção corrigida corroboram as observações de Ipharraguerre \& Clark (2003) de que a monensina promove efeito de diluição dos componentes no volume de leite.

Não foi verificado efeito das dietas para a porcentagem de lactose, principal constituinte e determinante do volume do leite, confirmando os valores observados para a produção de leite. A produção de proteína também não foi influenciada pelos tratamentos. Porém, enquanto a monensina aumentou a porcentagem de proteína do leite (2,87 vs 2,77\%), o óleo reduziu sua concentração (2,76 vs 2,87\%).

Freqüentemente, aumentos na concentração de proteína no leite são atribuídos à menor desaminação ruminal de aminoácidos pela ação da monensina (McGuffey et al., 2001) e à maior proporção de propionato no rúmen, que aumenta os níveis plasmáticos de glicose, diminuindo a proporção de aminoácidos para a gliconeogênese e que poderiam ser incorporados ao leite (Van Der Werf et al., 1998). Entretanto, Van Der Werf et al. (1998) somente observaram aumento na concentração de proteína do leite pelo uso de monensina em vacas de baixo mérito genético. Ainda não estão estabelecidas as causas da redução do teor de proteína pela adição de gordura dietética, mas, segundo De Peters (1993), a redução do teor de proteína pode estar associada ao efeito inibitório dos lipídios sobre a síntese microbiana e ao perfil de aminoácidos absorvidos no duodeno.
Dos componentes do leite, o mais afetado pelos tratamentos foi a porcentagem de gordura. Enquanto apenas as dietas com óleo reduziram a produção de gordura $(0,874$ vs $0,700 \mathrm{~kg} / \mathrm{dia})$, tanto óleo (3,35 vs $2,82 \%$ ) como monensina (3,23 vs $2,94 \%$ ) reduziram essa variável (Tabela 3). Enquanto as dietas sem óleo mostraram aumentos na concentração de gordura na $13^{\mathrm{a}}$ à $16^{\mathrm{a}}$ semana de lactação, a presença de óleo de soja proporcionou decréscimo no teor de gordura logo a partir da primeira fase avaliada (Figura 4A), refletindo sobre a produção de gordura (Figura 4B).

A literatura tem reportado diminuição no teor de gordura do leite quando monensina ou lasalocida é fornecida a vacas lactantes (McGuffey et al., 2001; Ipharraguerre \& Clark, 2003) e este efeito é ainda maior na presença de lipídios insaturados (Johnson et al., 1988; Cant et al., 1997). Recentemente, Jenkins et al. (2003) observaram, em ensaios in vitro, que a monensina promove um marcante aumento das concentrações de trans-10 $\mathrm{C}_{18: 1}$ como principal intermediário da bio-hidrogenação ruminal e que o aparecimento deste ácido graxo é potencializado quando o óleo de soja é associado à monensina. Griinari et al. (1998) associaram esse ácido graxo e seus correlatos à redução da gordura do leite, que inibe enzimas associadas à síntese de novo, à acetil CoA carboxilase e à enzima ácido graxo sintetase.

A análise dos ácidos graxos do leite neste trabalho (Eifert et al., 2005) confirma os resultados obtidos por Jenkins et al. (2003) e que a combinação de óleo de soja e de monensina interagiu no sentido de aumentar a concentração de trans-10 $\mathrm{C}_{18: 1}$, em nível mais 

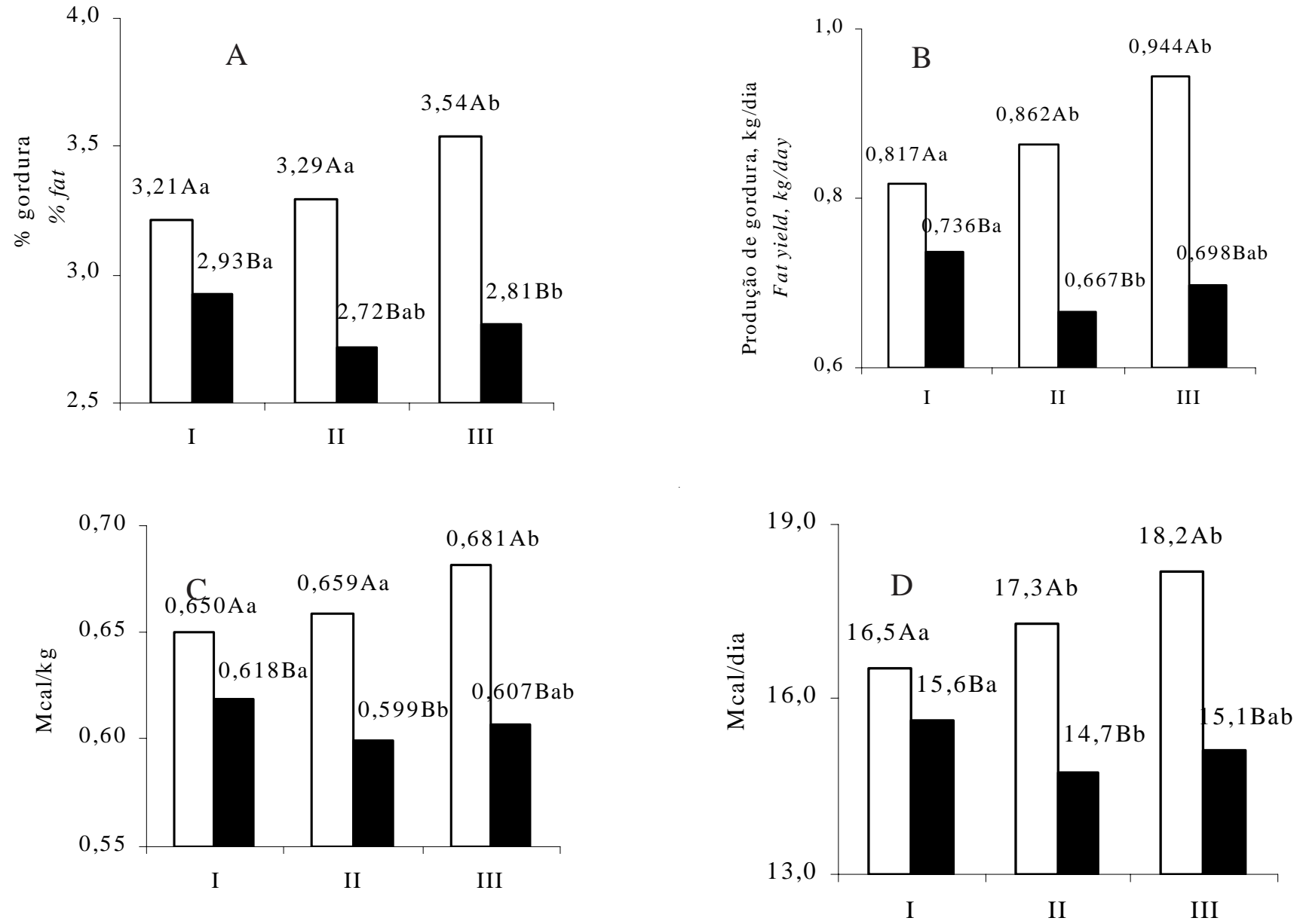

Figura 3 - Representação gráfica da interação óleo x fase da lactação das variáveis: porcentagem (A) e produção de gordura (B) e secreção de energia por unidade de leite (C) e diária (D). I, II, III - fase da lactação; $\square$ dietas sem óleo; - dietas com óleo. A, B - diferença na mesma fase; $a, b$ - diferença dentro do tratamento $(T u k e y, P<0,05)$.

Figure 3 - Graphic representation of the oil $x$ phase of lactation interaction of milk fat content $(A)$ and yield $(B)$ and energy secretion per milk unit (C) and daily (D). I, II, III - phase of lactation; $\square$ diets without oil; $\mathbf{\square}$ diets with oil. A, B - difference within phase of lactation; $a, b$ - difference within treatment (Tukey, $P<0.05$ ).

elevado que quando estes ingredientes foram fornecidos em separado. As médias observadas no leite para trans-10 $\mathrm{C}_{18: 1}$ foram de 0,37; 0,67; 1,86 e 2,31 g/100g para CT, MN, OL e OM, respectivamente. A redução no teor de gordura do leite coincidiu com os aumentos na concentração de trans-10 $\mathrm{C}_{18: 1}$ ( $\mathrm{r}=-0,6943 ; \mathrm{P}=0,0001)$ e o efeito inibitório de trans$10 \mathrm{C}_{18: 1}$ mostrou-se mais acentuado sobre os ácidos graxos de cadeia média, oriundos da síntese de novo ( $\mathrm{r}=-0,9279 ; \mathrm{P}=0,0001)$.

Em função da alteração dos conteúdos de gordura e proteína do leite, a relação proteína gordura foi aumentada tanto pelo óleo $(0,87$ vs 1,00$)$ como pela monensina $(0,88$ vs 0,99$)$. O aumento desta relação tem sido fator importante para a indústria de laticínios e para regiões em que se utilizam cotas de gordura do leite (Kennelly \& Glimm, 1998).
Ipharraguerre \& Clark (2003) afirmaram que aumentos na eficiência alimentar são características de dietas com ionóforos. Johnson et al. (1988) e Cant et al. (1997) observaram que a associação de ionóforos com gordura dietética proporcionou melhor eficiência alimentar que quando esses componentes são fornecidos isoladamente. Entretanto, neste trabalho, não se constataram efeitos da monensina ou da interação do ionóforo com óleo de soja sobre qualquer forma de expressão da eficiência.

McGuffey et al. (2001) criticaram a falta de padronização nas unidades utilizadas na obtenção dos valores que estimam eficiência. Na Tabela 3 são apresentadas três formas de expressão da eficiência e seus respectivos efeitos entre os tratamentos. O óleo apresentou maiores valores de eficiência bruta, calculada pela produção de leite dividida pelo consu- 
Tabela 4 - Médias observadas, desvio-padrão e efeitos principais do ganho de peso diário, escore corporal e balanço energético, em função da combinação de óleo de soja e monensina na dieta

Table 4 - Observed means, standard error and main effects of the dietary supplementation of soybean oil and monensin on daily weight gain, body score, and energetic balance

\begin{tabular}{|c|c|c|c|c|c|c|c|c|}
\hline \multirow[t]{2}{*}{ Item } & \multicolumn{4}{|c|}{$\begin{array}{l}\text { Média dos tratamentos } \\
\text { Mean of treatments }\end{array}$} & \multirow[t]{2}{*}{$\begin{array}{c}\text { DPM } \\
\text { SEM }\end{array}$} & \multicolumn{3}{|c|}{$\begin{array}{c}\text { Efeito }(\mathrm{P})^{2} \\
\operatorname{Effect}(P)\end{array}$} \\
\hline & CT & $\mathrm{MN}$ & $\mathrm{OL}$ & $\mathrm{OM}$ & & $\mathrm{M}$ & $\mathrm{O}$ & $\mathrm{MxO}$ \\
\hline PVI, kgILW, kg & 469,6 & 484,9 & 458,8 & 474,6 & 41,1 & $\mathrm{NS}^{2}$ & NS & NS \\
\hline $\begin{array}{l}\text { Ganho de peso, kg/dia } \\
\text { Weight gain, kg/day }\end{array}$ & 0,303 & 0,464 & 0,500 & 0,557 & 0,07 & NS & 0,06 & NS \\
\hline $\begin{array}{l}\text { EC inicial, pontos } \\
\text { CS initial, points }\end{array}$ & 2,63 & 2,75 & 2,75 & 2,75 & 0,20 & NS & NS & NS \\
\hline $\begin{array}{l}\text { EC final, pontos }{ }^{3} \\
\text { CS final, points }\end{array}$ & 3,00 & 3,13 & 3,13 & 3,25 & 0,38 & NS & NS & NS \\
\hline $\begin{array}{l}\text { Balanço energético } \\
\text { Energetic balance }\end{array}$ & 0,97 & 1,60 & 2,99 & 2,77 & 1,25 & NS & NS & NS \\
\hline
\end{tabular}

DPM = desvio-padrão da média (SEM = standard error of mean).

${ }^{1} \mathrm{CT}$ = sem óleo ou monensina; $\mathrm{MN}=$ monensina a $33 \mathrm{ppm} ; \mathrm{OL}=$ óleo de soja a $4 \% \mathrm{MS} ; \mathrm{OM}=$ óleo de soja + monensina .

${ }^{1} \mathrm{CT}=$ without oil or monensin; $M N=33$ ppm of monensin; $O L=4 \%$ of $D M$ as soybean oil; OM = with soybean oil and monensin.

${ }^{2} \mathrm{M}=$ monensina; $\mathrm{O}=$ ó leo; $\mathrm{M} \times \mathrm{O}=$ interação; $\mathrm{NS}=$ não-significativo $(\mathrm{P}>0,20)$.

${ }^{2} M=$ monensin; $O=$ oil; $M \times O=$ interaction; $N S=$ not significant $(P>0.20)$.

${ }^{3}$ Escore corporal: $1=$ muito magra; 5 = muito gorda.

${ }^{3}$ Body score: 1 = very thin; 5 = very fat.

mo de matéria seca (1,50 vs 1,64; $\mathrm{P}=0,12)$. Quando a produção foi corrigida para seu conteúdo de gordura e proteína (eficiência corrigida), não se verificaram efeitos dos tratamentos. Por outro lado, quando se avaliou a eficiência energética, calculada pela secreção diária de energia no leite dividida pelo consumo de energia líquida, as dietas com óleo apresentaram valores menores.

Aumento na eficiência bruta alimentar para as dietas com óleo justifica-se não somente pela redução no consumo, mas também pela maior eficiência de utilização da energia metabolizável dos ácidos graxos pelo animal (Chilliard, 1993). Por outro lado, a menor eficiência energética nas dietas com óleo indica que houve um desvio da energia consumida, outrora para produção de leite e seus componentes, para outras atividades metabólicas, como no maior ganho de peso diário $(0,383$ vs $0,529 \mathrm{~kg} / \mathrm{dia}$, Tabela 4). Entretanto, estas taxas de ganho de peso não refletiram em diferenças estatísticas para o estado corporal final ou o balanço energético, embora a presença na dieta de monensina, óleo de soja ou sua combinação na dieta tenha resultado em maiores valores de balanço energético que a dieta controle.

O desempenho reprodutivo não foi avaliado, em razão do pequeno número de animais utilizados. Entretanto, Staples et al. (1998) sugeriram que, além do maior aporte de energia pela inclusão de gordura na dieta, alguns lipídios insaturados agem como sinalizadores de processos fisiológicos no sistema reprodutivo, principalmente os ácidos linoléico, linolênico e eicosapentaenóico. Enquanto trabalhos têm sido desenvolvidos para se confirmar a influência destes ácidos graxos ou a função específica de algum isômero gerado na bio-hidrogenação ruminal, os resultados verificados para a recomposição corporal neste trabalho indicam que positivos efeitos reprodutivos podem ser esperados com a utilização de óleo de soja nas dietas (NRC, 2001).

\section{Conclusões}

A utilização de dietas com óleo de soja em combinação ou não com monensina promoveu redução no consumo de matéria seca, manteve a produção de leite e o consumo de energia, porém, reduziu a produção de leite corrigida.

Tanto óleo como monensina alteram a composição do leite e seus maiores reflexos são observados nos teores de gordura e proteína. A menor secreção de energia no leite nas dietas com óleo é compensada pelo maior ganho de peso dos animais.

\section{Literatura Citada}

AGRICULTURAL AND FOOD RESEARCH - AFRC. Energy and protein requirements of ruminants. Wallingford: $C A B$ International, 1993. 176p.

ALLEN, M.S. Effects of diet on short-term regulation of feed intake by lactating dairy cattle. Journal of Dairy Science, v.83, p.1598-1624, 2000. 
BENSON, J.A.; REYNOLDS, C.K.; HUMPHRIES, D.J. et al. Effects of abomasal infusion of long-chain fatty acids on intake, feeding behavior and milk production in dairy cows. Journal of Dairy Science, v.84, p.1182-1191, 2001.

CANT, J.P.; FREDEEN, A.H.; MacINTYRE, T. et al. Effect of fish oil on milk composition in dairy cows. Canadian Journal of Animal Science, v.77, p.125-131, 1997.

CHILLIARD, T. Dietary fat and adipose tissue metabolism in ruminants, pigs, and rodents: a review. Journal of Dairy Science, v.81, p.3897-3931, 1993.

DE PETERS, E.J. Influence of feeding fats to dairy cows on milk composition. In: CORNELL NUTRITION CONFERENCE FOR FEED MANUFACTURERS, 1993, Ithaca. Proceedings... Ithaca: Cornell University, 1993. p.199-215.

DRACKLEY, J.K. Biology of dairy cows during the transition period: the final frontier? Journal of Dairy Science, v.82, p.2259-2273, 1999.

DUFFIELD, T.F.; LESLIE, K.E.; SANDALS, D. et al. Effect of prepartum administration of monensin in a controlled-release capsule on milk production and milk components in early lactation. Journal of Dairy Science, v.82, p.272-279. 1999.

EIFERT, E.C.; LANA, R.P.; LEÃO, M.I. et al. Efeito da combinação de óleo de soja e de monensina na dieta sobre o consumo e digestão em vacas lactantes. Revista Brasileira de Zootecnia, v.34, n.1, p.293-308, 2005.

EIFERT, E.C.; LANA, R.P.; LANNA, D.P.D. et al. Perfil de ácidos graxos do leite de vacas alimentadas com óleo de soja e monensina no início da lactação. Revista Brasileira de Zootecnia, 2005 (em tramitação).

GAGLIOSTRO, G.; CHILLIARD, Y. Duodenal rapeseed oil infusion in early and midlactation cows. 2. Voluntary intake, milk production, and composition. Journal of Dairy Science, v.74, p.499-509, 1991.

GRIINARI, J.M.; DWYER, D.A.; MCGUIRE, M.A. et al. Trans-octadecenoic acids and milk fat depression in lactating dairy cows. Journal of Dairy Science, v.81, p.1251-1261, 1998.

IPHARRAGUERRE，I.R.; CLARK，J.H. Usefulness of ionophores for lactating dairy cows: a review. Animal Feed Science and Technology, v.106, p.39-57, 2003.

JENKINS, T.C.; FELLNER, V.; MCGUFFEY, R.K. Monensin by fat interactions on trans fatty acids in cultures of mixed ruminal microorganisms grown in continuous fermentors fed corn or barley. Journal of Dairy Science, v.86, p.324-330, 2003.

JENKINS, T.C. Symposium: advances in ruminant lipid metabolism - Lipid metabolism in the rumen. Journal of Dairy Science, v.76, p.3851-3863, 1993.
JOHNSON JR., J.C.; UTLEY, P.R.; MULLINIX, B.G. et al. Effects of adding fat and lasalocid to diets of dairy cows. Journal of Dairy Science, v.71, p.2151-2165, 1988.

KENNELLY, J.J; GLIMM, D.R. The biological potential to alter the composition of milk. Canadian Journal of Animal Science, v.78, Suppl. 1, p.23-56, 1998.

KNOWLTON, K.F.; ALLEN, M.S.; ERICKSON, P.S. Lasalocid and particle size of corn grain for dairy cows in early lactation. 1. Effect on performance, serum metabolites, and nutrient digestibility. Journal of Dairy Science, v.79, p.557-564, 1996

LEIVA, E.; HALL, M.B.; Van HORN, H.H. Performance of dairy cattle fed citrus pulp or corn products as source of neutral detergent-soluble carbohydrates. Journal of Dairy Science, v.83, p.2866-2875, 2000.

McGUFFEY, R.K.; RICHARDSON, L.F.; WILKINSON, J.I.D. Ionophores for dairy cattle: current status and future outlook. Journal of Dairy Science, v.84, Suppl. E, p.E194-E203.

NATIONAL RESEARCH COUNCIL - NRC. Nutrient requirements of dairy cattle. 7 .ed. Washington, $\mathrm{DC}$ : National Academy, 2001. 381p.

NATIONAL RESEARCH COUNCIL - NRC. Nutrient requirements of dairy cattle. 6.ed. Washington, DC: National Academy, 1989. 381p.

PHIPPS, R.H.; WILKINSON, J.I.D.; JONKER, L.J. et al. Effect of monensin on milk production of Holstein-Friesian dairy cows. Journal of Dairy Science, v.83, p.2789-2794, 2000.

STATISTICAL ANALYSES SYSTEM - SAS. SAS-STAT. The SAS system for windows version 8.0. Nashville: SAS Institut, 1999. CD-ROM. 1999.

STAPLES, C.R.; BURKE, J.M.; THATCHER, W.W. Influence of supplemental fats on reproductive tissues and performance of lactating cows. Journal of Dairy Science, v.81, p.856871, 1998.

Van Der WERF, J.H.J.; JONKER, L.J.; OLDENBROEK, J.K. Effect of monensin on milk production by Holstein and Jersey cows. Journal of Dairy Science, v.81, p.427-433, 1998.

Recebido em: 03/10/04 Aceito em: 14/06/05 